Journal of Agriculture and Social Research (JASR) Vol. 8, No. 2, 2008

\title{
APPROACHES FOR PREPARING AGRICULTURAL ADVISORY SERVICES FEASIBILITY STUDY
}

\author{
*SEYYED MAHMOUD HASHEMI, **SEYYED YOUSEF HEJAZI, AND ***IRAJ \\ MALEK MOHAMMADI \\ Department of agricultural extension and education, The University of Tehran, Iran \\ Telephone number: +98-21-2238293 \\ *Corresponding author's E-mail:seyyedmahmoodhashemi@gmail.com \\ Telephone number: +98-729-7622903(included Iran code) \\ Or cellular phone number: +989173295387;Fax no: +98-261-2818709
}

\begin{abstract}
According to present literature on agricultural extension organizations reforms, moving towards agricultural advisory services have become a paramount choice to perform these changes by policy makers and planners throughout the world especially in developing countries. The main purpose of this study was to propose some methods for doing agricultural advisory services feasibility studies. For doing so, three methods, which include project objectives-based approaches, force field analysis -based approaches, fitness between frame conditions and choice variables-based approaches have been introduced in this paper based on this critical assumption that there is no best practice or method for designing these services and it necessary to choose best fit agricultural advisory services.
\end{abstract}

Keywords: agricultural advisory services, feasibility study, agricultural extension

\section{INTRODUCTION}

As many agricultural extension experts have stated traditional public agricultural extension has been under serious pressure to reform since the 1990s. for example, Collion highlights pressures from (a) reductions in state budgets that are causing a downsizing in public services, (b) increasing information about extension's ineffectiveness, (c) lack of relevance and accountability, (d) poor performance in reaching low income and women farmers, (e) trends in decentralization that contradict the traditional top-down extension format, and (f) the emergence of new actors such as nongovernmental organizations (NGOs) that can educate farmers. So it is not unexpected also as Anderson reported in background paper for the world development report 2008 "after a period of neglect, agricultural advisory services have returned strongly to the international development agenda." So, various countries have different hopes such as moving towards demand-driven, decentralization, cost-recovery and outsourcing agricultural extension programs which be accountable to diverse needs of their target groups particularly small farmers and women by implementing agricultural advisory services (AAS).Therefore, some countries may jump to design AAS without doing the good feasibility study which can guarantee relevance of proposed AAS characteristics to their domestic conditions as a result of high pressure on their agricultural extension organizations. So, it is highly appropriate to investigate feasibility study doing alternatives for AAS design. As mentioned earlier the main purpose of this study is to do so.

\section{Agricultural advisory services (AASs)}

The term agricultural advisory services refer to the entire set of organizations that support and facilitate people engaged in agricultural production to solve problems and to obtain information, skills and technologies to improve their livelihoods (Ibid, 2008). In this paper, AASs has been considered as an option to reform traditional public agricultural extension in order to removing mentioned constrains and challenged in previous part. 


\section{Journal of Agriculture and Social Research (JASR) Vol. 8, No. 2, 2008}

\section{Feasibility study}

NFSMI define feasibility study as an evaluation or analysis of the potential impact of a proposed project or program. A feasibility study is conducted to assist decision-makers in determining whether or not to implement a particular project or program. The feasibility study is based on extensive research on both the current practices and the proposed project/program and its impact on the school foodservice operation (or other operations). (NFSMI, 2006) In this study, based on each of following proposed methods, will be a feasibility study definition.

\section{Feasibility study doing methods of AASs projects}

\section{A. Project's objectives-based approaches}

In this approach, the main focus is on the objectives of advisory services and national agricultural policy .If we consider AASs components based on The Extension Research Group at IFPRI framework (see Fig., 1 ) for designing and analyzing agricultural advisory services, these services composed of three parts including:

(a) Governance structures: Role of the public, the private and the third sector in providing and financing the service; decentralization to lower levels of government;

(b) Capacity and management: Financial and human resources available, relative to the number of farmers to be reached; management system (incentives to extension personnel, supervision and reporting; results-orientation); and

(c) Advisory methods: Numbers of clientele involved (individual, group-based or mass methods); type of training and technology transfer (demonstration plots; field days; courses; farmer-to-farmer exchange; involvement of clients into planning and problem-solving (participatory vs. top-down), specificity of content; type of media used; adult-educationorientation.

In this case, according to this approach, an evaluator (someone or a group whose job is preparing feasibility study) should at first determine objectives of advisory services and national agricultural policy and then he/she investigate level of relevance between both of them. If this comparison showed that there is acceptable and reliable level of relevance he /she can enter next step. Otherwise advisory services objectives should revise according to national agricultural policy because usually the former are more flexible to change than latter. The next step is to determine whether three parts of AASs proposed by IFPRI are relevant to (revised) objectives of advisory services .In other words, this step should confirm that relying on these AASs characteristics ( 3 parts) cause to gain objectives of advisory services. So based on this approach, as mentioned above, the most important factor which evaluator should take into account are objectives of AASs project, therefore feasibility study is defined as analysis of AASs project components in order to determine whether these components have necessary potential to help planners to reach project or programs objectives.

This method should be used when evaluator wants to prepare a feasibility study quickly and usually he/she deals with small projects which are not very important its probable failures or in situations which project's effectiveness is important than other indicators for evaluator. One of the major weakness points of this method is lack of attention to or suitable concentration on other factors besides project's objectives in other words, evaluator limit all of his/her analysis and calculation to project's objectives so it may cause him/her to ignore effects of other factors on project. However in situations which evaluator wants to know about general information related to viability of proposed project rapidly, this method can be a good option. 
Journal of Agriculture and Social Research (JASR) Vol. 8, No. 2, 2008

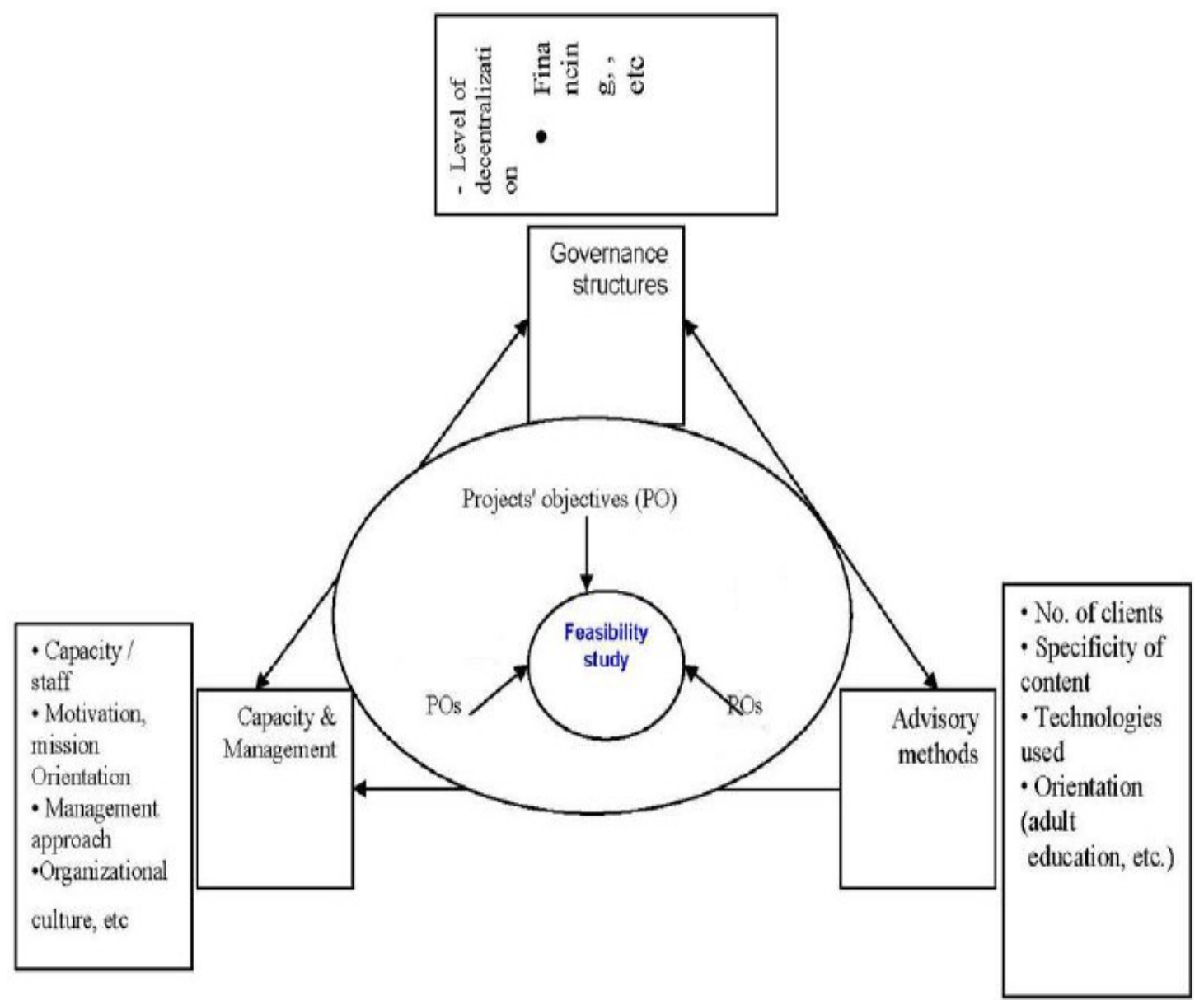

Fig., 1 - Framework for agricultural advisory services making feasibility study (adapted from Regina Birner et al, 2006)

\section{B. Force field analysis -based approaches}

Two concepts are important in this method to begin feasibility study. First driving forces which are those forces affecting a situation that are pushing in a particular direction; they tend to initiate a change and keep it going. In terms of AASs, educated and skillful agricultural advisors, using participatory methods for diffusion of innovations and existence of competition in delivery of agricultural services may be examples of driving forces. And next is restraining forces which are forces that work against the change. Using supply-driven approach and prevalence of fragmented lands may be examples of restraining forces against AASs establishment. As you see in Fig., 1, in terms of AASs, in fact current state is traditional public extension while AASs is desired state, therefore to transform the former in order to reaching the latter, there are some driving and restraining forces which to total the For and Against forces against establishment of AASs project can determine viability probability of proposed project. 
Journal of Agriculture and Social Research (JASR) Vol. 8, No. 2, 2008

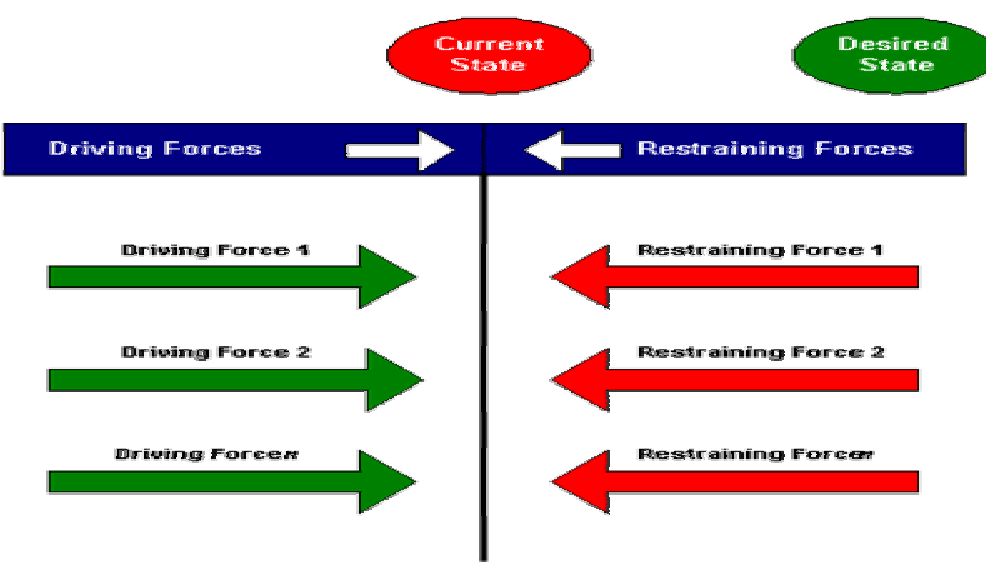

Fig., 2 - Force Field Analysis of a General Problem

To do feasibility study based on this method, at first evaluator should determine driving and restraining forces, based on facilitating or hampering potential to gain AASs objectives. In next step, he/she should give each factor a score of between 1 and 5, where 1 is low or weak and 5 is high or strong, and then as mentioned earlier, should be total the For and Against forces scores. Finally evaluator will be able to estimate viability of project based on previous stage (calculated score).

In this perspective, feasibility study is defined an analysis whose job is to determine viability probability of AASs project by calculation of difference between driving and restraining forces.

This method should be used when evaluator wants to prepare a feasibility study more accurately than previous method in relatively easy case. As mentioned because of this method focuses on seeking of driving and restraining forces, evaluator may not be able to find total amount of both of forces and as a result, results of this analysis can be valid and reliable.

\section{Fitness between frame conditions and choice variables -based approaches}

The critical assumption for conducting the AASs feasibility study is to shift from a "one-sizefits-all" to a "best fit" approach in the reform of public services and establishment of AASs. Therefore, at first evaluator should determine frame conditions and choice variables for establishment of AASs. The characteristics of agricultural advisory services - their governance structures, capacity, organization and management and advisory methods - are choice variables. They are displayed in Boxes G, M and A in Fig., 2 .The frame conditions, which have to be taken into account when making choices on the design of advisory services, are displayed in Boxes E, S, F and C(see Fig., 2).

As mentioned above because of some countries may jump to design AASs without doing the good feasibility study which can guarantee relevance of proposed AASs characteristics (choice variables) to their domestic conditions (frame conditions), from this perspective, this approach is an ideal method to do an AASs feasibility study which can guarantee mentioned relevancy. 
Journal of Agriculture and Social Research (JASR) Vol. 8, No. 2, 2008

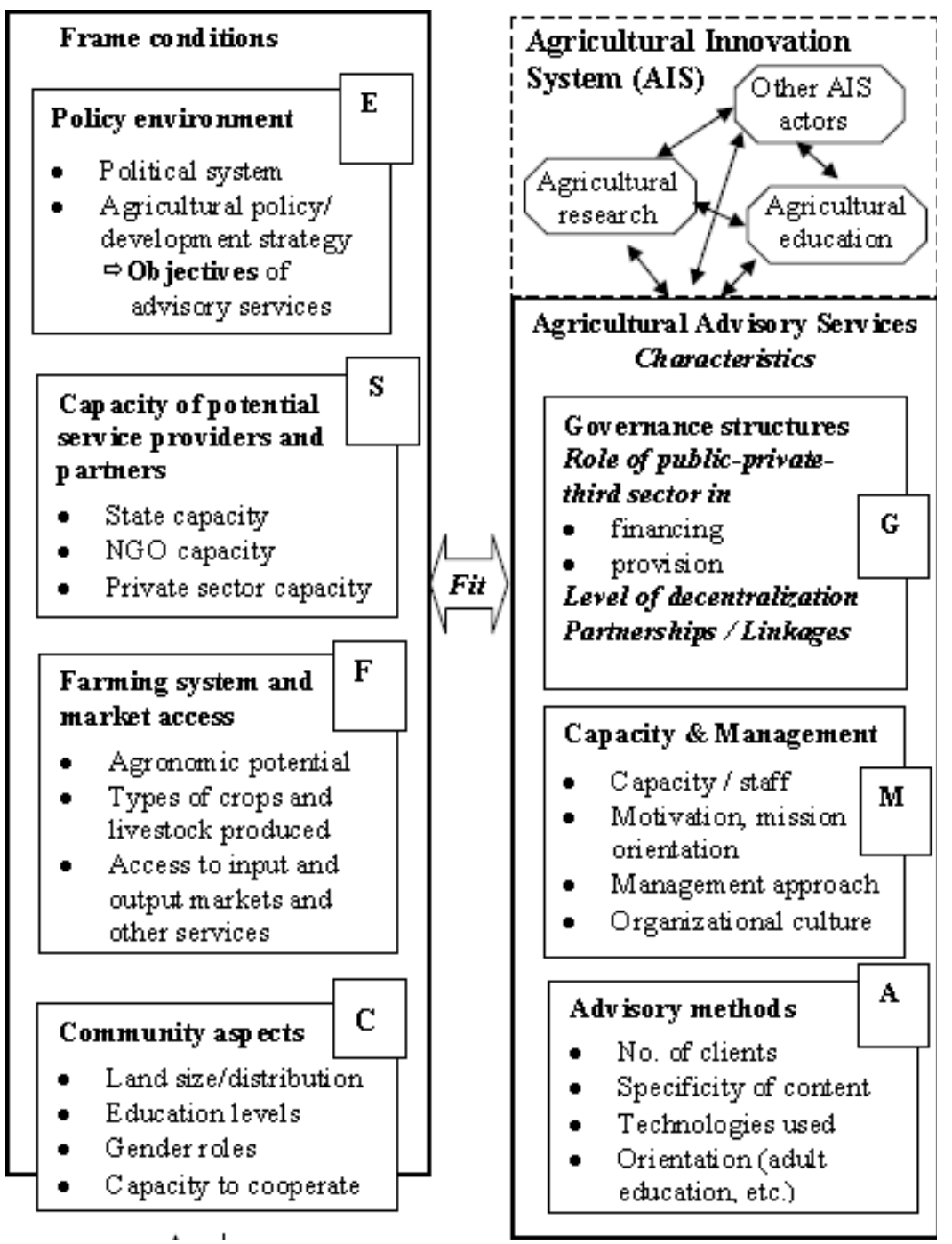

Fig., 3.Framework for Designing and Analyzing Agricultural Advisory Services (Source: Regina Birner et al, 2006)

To do AASs feasibility study according to this method, evaluator should determine fitness level between frame conditions which are not flexible to change them and proposed AASs characteristics which are more flexible to change (see Fig., above). In other words, choice variables should be select based on frame conditions. After comparison of mentioned factors, evaluator will be able to recommend revising choice variables in order to more fitness. Of course, evaluators should take interactions and mutual impacts among AASs characteristics (Boxes G, M and A in Fig., 2) into account to do feasibility study.

In this case, feasibility study is defined an analysis whose job is to determine viability probability of AASs project by determination of fitness level among frame conditions and choice variables. This method should be used when evaluator wants to prepare a holistic feasibility study and usually when he/she deals with national or macro level project which project's failure can have very adverse impacts on its clients and other components. In other words, this method is a combination of previous two methods which can guarantee to gain project's objectives and implementation of forces field analysis indirectly. Of limitations of this method for preparing AASs feasibility study is included to need a skillful and multidisciplinary group of evaluators. 
Journal of Agriculture and Social Research (JASR) Vol. 8, No. 2, 2008

\section{CONCLUSION}

This paper reviewed some methods to do feasibility study for agricultural advisory services projects. As mentioned each method has own advantages and disadvantages. Of important factors for selection of them are evaluator's objectives and scale and importance of proposed project. As mentioned, project's objectives-based approaches should be used when evaluator wants to prepare a feasibility study quickly and one of the major weakness points of this method is lack of suitable concentration on other factors besides project's objectives. Force field analysis -based approaches should be used when evaluator wants to prepare a feasibility study more accurately than previous method in relatively easy case. And because of this method focuses on seeking of driving and restraining forces, evaluator may not be able to find total amount of both of forces and as a result, results of this analysis can be valid and reliable. And finally the most important strength point in fitness between frame conditions and choice variables -based approaches is conducting the AASs feasibility study based on shifting from a "one-size-fits-all" to a "best fit" approach in the reform of public services and establishment of AASs.

\section{REFERENCES}

Anderson, J., 2007. Agricultural Advisory Services. A background paper for "Innovating through science and technology", Chapter 7 of the WDR 2008

Birner, Regina; Davis, Kristin; Pender, John; Nkonya, Ephraim; Anandajayasekeram, Ponniah; Ekboir, Javier; Mbabu, Adiel; Spielman, David; Horna, Daniela; Benin, Samuel; Cohen, Marc J.,2006. From "Best Practice" To "Best Fit": A Framework For Analyzing Pluralistic Agricultural Advisory Services Worldwide DSGD Discussion Paper No. 37.a

Collion, M.-H. "Introduction to Revitalization within Public Sector Services." Extension Reform for Rural Development: Case Studies of International Initiatives. William Rivera and Gary Alex (editors). The World Bank, Rural Development Family, SASKI, Washington, D.C. October 15, 2002.

National food service management institute, 2006 The University of Mississippi, on line at: http://www.nfsmi.org/ 